\title{
A oportunidade perdida: a omissão legislativa para as propagandas sobre bebidas alcoólicas
}

Opportunity losted: the legislative omission for advertisements on alcoholic drinks

Oportunidad perdida: la omisión legislativa para la publicidad de las bebidas alcohólicas

Edith Maria Barbosa Ramos ${ }^{1}$ Sandra Mara Campos Alves ${ }^{2}$

ADO 22 / DF - Distrito Federal

AÇÃO DIRETA DE INCONSTITUCIONALIDADE POR OMISSÃO

Relator(a): Ministra Cármen Lúcia

Julgamento: 22/04/2015 Órgão Julgador: Tribunal Pleno

Publicação

DJe-151 DIVULG 31-07-2015 PUBLIC 03-08-2015

\section{Parte(s)}

Requerente. (s): Procurador-geral da República

Intimado. (a/s): Presidente da República

Intimado (a/s): Congresso Nacional

Advogados (a/s): Advogado-geral da União

Amicus Curiae: Associação Brasileira da Indústria da Cerveja - CERVBRASIL

Advogados (a/s): André Cyrino e outro(a/s)

Amicus Curiae: Associação Brasileira das Emissoras de Rádio e Televisão - ABERT

Advogados(a/s): Eduardo Antônio Lucho Ferrão e outro(a/s)

Amicus Curiae: Associação Brasileira de Psiquiatria - ABP

Advogados (as): Alan Vendrame e outro(a/s)

EMENTA: AÇÃO DIRETA DE INCONSTITUCIONALIDADE POR OMISSÃO. REGULAMENTAÇÃO DE PROPAGANDA DE BEBIDAS DE TEOR ALCOÓLICO INFERIOR A TREZE GRAUS GAY LUSSAC (13 GL). AUSÊNCIA DE OMISSÃO. ATUAÇÃO DO PODER LEGISLATIVO. ART. 2 DA CONSTITUIÇÃO DA REPÚBLICA. IMPOSSSIBILIDADE DE ATUAR O SUPREMO TRIBUNAL FEDERAL COMO LEGISLADOR POSITIVO, SUBSTITUINDO-SE AO PODER

Decisão: O Tribunal, por maioria, conheceu da ação, vencido o Ministro Marco Aurélio, que declarava o autor parcialmente carecedor da ação. Por unanimidade, julgou improcedente a ação, acentuando-se que, transitada em julgado, esta decisão tem efeito vinculante, tudo nos termos do voto da Relatora. Impedido o Ministro Teori Zavascki.

\footnotetext{
${ }^{1}$ Advogada. Pós-Doutorado pela Fundação Oswaldo Cruz Brasília. Professora da Faculdade de Direito da UFMA

2 Advogada. Doutoranda em Saúde Coletiva pela Universidade de Brasília-UnB. Professora e Pesquisadora da Fundação Oswaldo Cruz.
} 
Ausente, justificadamente, o Ministro Roberto Barroso, que representa o Tribunal na "Brazil Conference", na Universidade de Harvard, e na "Brazilian Undergraduate Student

Conference", na Universidade de Columbia, Estados Unidos. Falaram, pelo amicus curiae Associação Brasileira da Indústria da Cerveja - CERVBRASIL, o Dr. Gustavo Binenbojm, $\mathrm{OAB} / \mathrm{RJ}$ 83.152, e pelo amicus curiae Associação Brasileira das Emissoras de Rádio e

Televisão - ABERT, o Dr. Eduardo Antônio Lucho Ferrão, OAB/DF 9378. Presidiu o julgamento o Ministro Ricardo Lewandowski. Plenário, 22.04.2015.

Com três anos de atraso, o Supremo Tribunal Federal (STF) decidiu, por unanimidade, que não the cabe estabelecer restrições à publicidade de bebidas cujo teor alcoólico seja inferior a $13 \mathrm{GL}$. Para os Ministros as restrições sobre a propaganda de bebida alcoólica já estão plenamente regulamentas na Lei 9.294/961 e nas normativas do Conselho Nacional de Autorregulamentação Publicitária (CONAR). Com esse entendimento o desejo do setor da saúde viu-se frustrado no desejo de restringir a publicidade de bebidas alcoólicas.

A ação direta de inconstitucionalidade por omissão prevista na Constituição Federal $^{2}$, tem o objetivo de provocar o Supremo Tribunal Federal (STF) quando as omissões legislativas do Congresso Nacional forem capazes de inviabilizar a eficácia de normas constitucionais. O STF é conhecido como o guardião da Constituição, tem a função de garantir a harmonia e o cumprimento dos dispositivos constitucionais, assumindo a função de evitar a ausência normativa que impeça a efetivação concreta e imediata de direitos previstos na Carta Política de 1988.

Em virtude dessa função, a Procuradoria-Geral da República (PGR), em 2012, ajuizou Ação Direta de Inconstitucionalidade por Omissão $n^{\circ} 22(A D O)^{3}$ com o objetivo de questionar a omissão legislativa do Congresso Nacional em virtude da ausência de norma regulamentadora sobre os limites das propagandas de bebidas alcoólicas no Brasil.

Em 1996, um dispositivo constitucional sobre restrições ao uso e à propaganda de produtos fumígeros, bebidas alcoólicas, medicamentos, terapias e defensivos agrícolas foi regulamentado pela Lei $n^{\circ} 9.294$. Essa lei restringiu a propaganda apenas às bebidas com teor alcoólico superior a $13^{\circ} \mathrm{GL}$, mas o objetivo da ADO era a de estender a 
restrição legal à propaganda a todas as bebidas alcóolicas, independentemente de seu teor alcoólico, atendendo a uma reivindicação antiga do setor da saúde.

Falcão e Rangel-S ${ }^{4}$ observam a existência de 67 projetos de lei sobre o controle da propaganda de bebidas alcoólicas nos meios de comunicação de massa que se mantêm sem tramitação, no Congresso Nacional. Após 27 anos da promulgação da Constituição Federal e mais de 19 anos da Lei no 9.294/1996, o poder legislador do Estado não regulamentou as restrições referentes à publicidade de bebidas alcoólicas com teor inferior a $13^{\circ} \mathrm{GL}$.

A Corte Suprema julgou improcedente a ação proposta pela PGR, por unanimidade. A ministra-relatora da ação entendeu improcedente a alegação da PGR, firmando entendimento de que a temática da restrição de propaganda de bebidas com teor inferior a $13^{\circ} \mathrm{GL}$ é competência apenas do Congresso Nacional.

Embora a Lei no $11.705 / 08^{5}$ (Lei Seca) tenha considerado bebida alcoólica aquela com concentração igual ou superior a $0,5^{\circ} \mathrm{GL}$, a ministra relatora entendeu que essa normatização não contraria a especificidade da Lei 9.294/96, tendo em vista que os documentos legais têm objetivos diversos: a primeira restringe o uso de álcool por motoristas, enquanto a segunda tem por finalidade regular a publicidade de certos tipos de bebidas alcoólicas. Em sua decisão, reforça que a Lei 9.294/96 ao disciplinar e restringir a propaganda de bebidas, com concentração de álcool superior a $13^{\circ} \mathrm{GL}$, não nega o teor alcoólico das demais bebidas com concentração alcoólica inferior ao padrão de medição.

Essa posição jurídico-política vai de encontro com as prioridades de saúde e a estratégia global para reduzir o uso nocivo do álcool que traz prejuízo à saúde e consequências sociais para aquele que consome, para as pessoas a sua volta e para a sociedade em geral, bem como o aumento do risco de resultados adversos à saúde ${ }^{6}$. A visão dessa estratégia é melhorar os resultados de saúde dos indivíduos, famílias e comunidades, reduzindo a morbidade e mortalidade por uso nocivo do álcool e suas consequências sociais.

No Brasil, dados da $\mathrm{OMS}^{7}$, do ano de 2012, indicam que o consumo do álcool está associado a altos índices de cirrose hepática e a acidentes de trânsito. Estima-se que $5,6 \%$ dos brasileiros sejam acometidos de transtornos relacionados ao uso do álcool. 
As restrições à propaganda de bebidas são frágeis e assistemáticas, porque o Brasil adotou um modelo normativo caracterizado pela regulação sem intervenção externa, realizada pelo CONAR, que focaliza suas regras sobre o consumo do álcool, fundamentalmente, na exposição de menores de idade.

Pinsky e Jundi ${ }^{8}$ afirmam que as estatísticas brasileiras estão coerentes com a avaliação da Organização Mundial da Saúde (OMS) na América do Sul sobre a estimativa de vidas comprometidas por adoecimento e morte precoce, que gira em torno de 8 a 15\% da população e que o estímulo para o consumo do álcool é sua promoção por meio de propaganda, que associa seu consumo com os esportes, estilos de vida, identidades culturais à alegria do futebol e do carnaval.

A decisão conservadora do STF, na ADO $n^{0} 22^{3}$ quanto a omissão legislativa pretendida pela PGR, no que se refere às lacunas prejudiciais à saúde da Lei 9.294/961 revela as vulnerabilidades e violações de direitos fundamentais sociais e incompreensão do sistema de saúde pública no Brasil pela mais alta corte de justiça do país. Perdeu a oportunidade de corrigir a lacunosa e prejudicial Lei 9294/96 ${ }^{1}$, podendo julgar a favor da saúde, impondo ao Poder Legislativo federal a obrigação de legislar corrigindo-se uma omissão. 


\section{Referências}

1 Brasil. Lei 9.294, de 15 de julho de 1996. Disponível em:

<http://www.planalto.gov.br/ccivil_03/leis//9294.htm>. (Acesso em 5 fev. 2015.)

2 Brasil. Constituição da República Federativa do Brasil de 1988. Disponível em: $<$ http://www.planalto.gov.br/ccivil_03/constituicao/constituicao.htm>. (Acesso em 5 fev. 2015).

3 Brasil. Supremo Tribunal Federal. ADO. 22. Ação Direta de Inconstitucionalidade por Omissão. Relator: Min. Cármen Lúcia. Brasília, 13 de março de 2013. Disponível em: < http://stf.jusbrasil.com.br/jurisprudencia/23075556/acao-direta-de-inconstitucionalidadepor-omissao-ado-22-df-stf> (Acesso em 6.fev.2015)

4. Falcao, Isa Cristina Lopes. Rangel-S, Maria Ligia. Controle sanitário da propaganda de bebidas alcoólicas no Brasil: estudo dos projetos de lei de 1988 a 2004. Ciênc. saúde coletiva. 2010, vol.15, suppl.3, pp. 3433-3442.

5. Brasil. Lei 11.705, de 19 de junho de 2008. Disponível em:

<http://www.planalto.gov.br/ccivil_03/_ato2007-2010/2008/lei/111705.htm>. (Acesso em 5 fev. 2015).

6. Organização Mundial da Saúde. Global status report on alcohol and health. 2014. Disponível

em: <http://www.who.int/substance_abuse/publications/global_alcohol_report/msbgsruprofile s.pdf>. (Acesso em 15 mar. 2015).

7. Organização Mundial da Saúde. Global status report on alcohol and health. 2014. Disponível em: $<h t t p: / / w w w . w h o . i n t / s u b s t a n c e$ abuse/publications/global_alcohol_report/msbgsruprofile s.pdf>. (Acesso em 15 mar. 2015).

8.Pinsky, I. EI Jundi, SARO impacto da publicidade de bebidas alcoólicas sobre o consumo entre jovens: revisão da literatura internacional, Rev Bras Psiquiatr 2008;30(4):362-74, <http://www.scielo.br/pdf/rbp/v30n4/213.pdf >. (Acesso em 16. Jan.2008). 